\title{
EFECTOS AUTOFICCIONALES EN LA NINFA INCONSTANTE, DE GUILLERMO CABRERA INFANTE
}

\author{
EFEITOS AUTOFICCIONAIS EM LA NINFA INCONSTANTE, DE \\ GUILLERMO CABRERA INFANTE
}

\section{AUTOFICTIONAL EFFECTS IN LA NINFA INCONSTANTE, BY GUILLHERMO CABRERA INFANTE}

\author{
José Veranildo Lopes da COSTA JUNIOR*
}

\begin{abstract}
Resumen: En este artículo, presentamos una lectura de la novela póstuma La ninfa inconstante (2008), del escritor cubano Guillermo Cabrera Infante bajo la perspectiva de la autoficción. En relación a este análisis, nos interesa específicamente problematizar algunas construcciones narrativas que permiten un acercamiento entre la historia vivida por el protagonista de la novela y la vida de Cabrera Infante, resultando en un retorno a La Habana desde la memoria del narrador-protagonista.
\end{abstract}

Palabras clave: Cabrera Infante. La ninfa inconstante. Autoficción.

Resumo: Neste artigo, apresentamos uma leitura do romance póstumo La ninfa inconstante (2008), do escritor cubano Guillermo Cabrera Infante sob a perspectiva da autoficção. Em relação a esta análise, interessa-nos especificamente problematizar algumas construções narrativas que permitem uma aproximação entre a história vivida pelo protagonista do romance e a vida de Cabrera Infante, resultando em um retorno a La Havana a partir da memória do narrador-protagonista.

Palavras-chave: Cabrera Infante. La ninfa inconstante. Autoficção.

Abstract: This paper presents an autofictional reading perspective of the novel La ninfa inconstante (2008), by Guillermo Cabrera Infante. It provides a parallel narrative constructions of the narratorprotagonist that approximates the novel's protagonist and the author's lives, which results in a return to La Havana.

Keywords: Cabrera Infante. La ninfa inconstante. Autofiction.

\section{Introducción}

Según la física cuántica se puede abolir el pasado o, peor todavía, cambiarlo. No me interesa eliminar y mucho menos cambiar mi pasado. Lo que necesito es una máquina del tiempo para vivirlo de nuevo. Esa máquina es la memoria. Gracias a ella puedo vivir ese tiempo infeliz, feliz a veces. Pero, para suerte o desgracia, solo puedo vivirlo en una sola dimensión, la del recuerdo.

Cabrera Infante, 2008, p. 11.

\footnotetext{
* Professor Adjunto do Departamento de Letras Estrangeiras da Universidade do Estado do Rio Grande do Norte (UERN) - Campus Avançado de Pau dos Ferros. Doutor em Letras pela UERN. E-mail: jveranildo@hotmail.com
} 
Nacido en Gibara, en la isla cubana, el 22 de abril de 1929 y fallecido en Londres el 21 de febrero de 2005, Guillermo Cabrera Infante fue un importante escritor y crítico cinematográfico, además de un activista anti-castrista que ayudó a exportar la cultura habanera al mundo europeo. En su narrativa, además de La Habana haberse convertido en un espacio geográfico capaz de movilizar sentimientos, gustos, sabores e imágenes de un hogar afectivo para el escritor, la primera persona del discurso se vuelve en uno de los más recurrentes mecanismos de escritura de su proyecto literario.

Su obra de estreno sale en 1960 y se intitula Así en la paz como en la guerra. En 1965 tenemos la publicación de tres tristes tigres, considerada una de sus novelas más leídas por la crítica especializada en literaturas caribeñas que, incluso, recibió el premio Biblioteca Breve. Otros títulos, tales como Vista del amanecer en el trópico (1974), Todo está hecho con espejos (1999), Mea Cuba (1992), Holy Smoke (1985) ${ }^{1}$, demuestran que Cabrera Infante fue un escritor productivo a lo largo de su vida y que su obra construye un pensamiento sobre Cuba y la Revolución.

Antes de fallecer, Cabrera Infante dio a su mujer Miriam Gómez la tarea de publicar algunas de sus obras que no habían sido concluidas. Desde el conjunto de las llamadas obras póstumas del autor, se encuentra la novela La ninfa Infante, la cual será analizada en este artículo bajo la perspectiva de las escrituras autoficcionales.

Esta novela cuenta la historia de un crítico de cine llamado G. que trabaja para la revista Carteles $^{2}$. Al lado de su amigo Branly, el protagonista conoce a una seductora ninfa llamada Estela Moris ${ }^{3}$. Como ya mencionado en este artículo, en su vida, Cabrera Infante se dedicó a la crítica de cine, incluso, llegó a publicar algunos ensayos sobre el séptimo arte, como Un oficio del siglo XX (1963), Arcadia todas las noches (1978) y Cine o sardina (1997). Iván Darancou (2014), por ejemplo, nos recuerda que la solapa de la edición de La ninfa inconstante publicada por Galaxia Gutenberg (2008) trae la información que Cabrera Infante empezó a trabajar en Carteles como crítico cinematográfico bajo el seudónimo de G. Cain. En este sentido, el acercamiento del nombre del personaje ficcional de esta novela, o sea, G. a Guillermo o a G. Cain, puede ser entendido como un efecto de la autoficción en su escritura al crear un juego a partir del seudónimo adoptado por Cabrera Infante. Además de eso, la edición de Galaxia Gutenberg es abierta con una cita que afirma:

\footnotetext{
${ }^{1}$ Obra originalmente escrita en inglés y traducida al castellano bajo el título Puro Humo, en el año 2000.

${ }^{2}$ Revista cubana fundada en el año 1919.

${ }^{3}$ El narrador utiliza algunos sinónimos para su nombre, como Stella Moris o Estelita.
} 
Si encuentras anglicismos, corrector de pruebas que no apruebas, no los toques: así es mi prosa. Déjenlos ahí quietos en la página. No los muevan. Después de todo, esta narración está escrita en Inglaterra, donde he vivido más de treinta años. Una vida, como diría, mi tocayo Guy de Maupassant, en passant. De mot passant (CABRERA INFANTE, 2008, p.10).

Este autor parece crear, a través de esta citación, una advertencia a un tipo de lector no conocedor de los cruces entre historia y ficción, o entre realidad y literatura presentes en la escritura de Cabrera Infante, y advierte: "así es mi prosa”, “escrita en Inglaterra”, dónde estuvo más de treinta años exilado. Tras esta nota de apertura, La ninfa inconstante empieza con un Prólogo, que parece tener la función de ubicar esta narrativa en los límites de la literatura, entre la historia y la ficción, pues.

Es necesario volver al epígrafe que abre nuestro artículo, que es también el primer párrafo del mencionado Prólogo. En primera persona, el autor afirma que no se puede eliminar o cambiar el pasado. Así, tenemos otro cruce entre la vida privada del autor y la literatura, a la vez que Cabrera Infante fue un crítico de Fidel Castro y por eso vivió el exilio en Europa. Para él, no se puede eliminar un pasado de persecución política en Cuba y tampoco se puede olvidar la vida que tuvo en la isla. De acuerdo con Iván Darancou (2014, p. 482):

Para Cabrera Infante, lo que importa es recordar La Habana como era antes de la llegada de la Revolución, no en un afán explícitamente anticomunista, sino en el intento de salvar en la memoria lo que la historia deja de lado al sujetarse a un filtro ideológico, ya sea cubano o en el exilio.

La ninfa inconstante es un retorno posible del autor a la isla cubana desde una "máquina del tiempo", o sea, la memoria. Ese reencuentro con la vieja Habana se da a partir de la dimensión del recuerdo, y así "los fotones pueden negar el pasado, pero siempre se proyectan sobre una pantalla - en este caso este libro. La única virtud que tiene mi historia es que de veras ocurrió" (CABRERA INFANTE, 2008, p. 11).

La narrativa autoficcional contada en las páginas de la novela póstuma de Cabrera Infante dialoga con otras obras de la literatura hispanoamericana. La trama trata del encuentro entre G., el crítico de cine, un verdadero intelectual latino-americano que conoce referencias importantes de la literatura occidental y habla con letras de boleros famosos y Estela Moris, una ninfa seductora que no entiende sus referencias culturales.

Este clásico enredo es el tema de otras novelas latinoamericanas como, por ejemplo, Memoria de mis putas tristes (2004), de Gabriel García Márquez, cuya historia retrata el encantamiento de un viejo de 90 años con una adolescente virgen y empieza con las siguientes 
palabras: "el año de mis noventa años quise regalarme una noche de amor loco con una adolescente virgen" (GARCÍA MÁRQUEZ, 2004, p. 05).

La novela cubana y la colombiana, para citar dos ejemplos de la literatura hispanoamericana, además de las herramientas autoficcionales utilizadas en su construcción discursiva, también pueden ofrecer una clave de lectura fundamentada en la crítica feminista. Estas narrativas tratan de un supuesto encantamiento de hombres mayores a adolescentes de menor edad, y aunque el sexo se convierta en algo secundario, pero demasiado deseado, estas historias parecen mostrar que hombres más viejos (en el caso de Memorias de mis putas tristes, tenemos un anciano de 90 años de edad) se sienten confortables en buscar relaciones sexuales con adolescentes vírgenes. Estes hombres saben que estas relaciones son prohibidas en gran parte de las sociedades del mundo occidental y, por eso, culpabilizan las adolescente de seducción.

Teniendo, pues, en cuenta esa aproximación entre La ninfa inconstante y algunas cuestiones importantes discutidas en clásicos de la literatura de nuestro continente, en este artículo, haremos un análisis de la novela póstuma de Cabrera Infante percibiendo aspectos narrativos que producen efectos autoficcionales, responsables por crear un juego entre la realidad y la ficción o entre la vida privada del autor y la ficción. Este efecto autoficcional forma parte de una tradición memorialística de la narrativa latinoamericana, que toma la forma de autobiografías (MOLLOY, 2003) o de textos autoficcionales ubicados entre los límites de la realidad y de la ficción (ALBERCA, 2006; KLINGER, 2007).

\section{Construcciones autoficcionales}

Habrá momentos en que el ojo que lee no creerá lo que ve. Eso se llama ficción. Pero es necesario siempre que el lector confunda el presente de la lectura con el pasado de lo narrado y que ambos tiempos avancen en busca de un futuro que es la culminación de la acción en la narración.

Cabrera Infante, 2008, p. 12.

No es novedad que la novela hispanoamericana se caracteriza por bifurcaciones entre historia y realidad o entre lo documental y la ficción. Diana Klinger (2007), al analizar la narrativa latinoamericana, afirma que parte de los textos contemporáneos son marcados por dos tendencias: un retorno del autor, entendido como el narrador que presenta marcas autobiográficas y una virada etnográfica, que dice respecto a una escritura sobre un mundo subalterno. Para ella, las narrativas que desarrollen por lo menos uno de los dos trazos "problematizam a ideia de referência e assim incitam a abandonar os rígidos binarismos entre fato e ficção" (KLINGER, 2007, p.13). 
A su vez, al hacer un análisis de un estudio del crítico venezolano Gustavo Guerrero, Manuel Alberca (2006) afirma que otros dos rasgos caracterizan las literaturas actuales producidas en nuestro continente: la hibridación y la mezcla de los géneros. Para el autor, la literatura hispanoamericana del tiempo presente se materializa a partir de una escritura que pone la experiencia de "yo" en primera persona como eje central en la construcción discursiva. Este cruce entre vida privada y ficción aparece oficialmente, por primera vez, en Europa, "quando, em 1977, o escritor e crítico francês Serge Doubrovsky forjou o termo “autoficção" para definir o pacto de leitura do seu romance Fils" (NORONHA, 2014, p. 07).

De acuerdo con Alberca (2006, p.07), aunque podemos decir que los textos autoficcionales son de la misma familia de las autobiografías tradicionales, "en ningún caso debemos confundirlas, pues en las segundas el autor se encarna total o parcialmente en un personaje novelesco, se oculta tras un disfraz ficticio". A este respecto, como ya mencionado anteriormente y bien explicado por Iván Darancou (2014), Cabrera Infante se oculta, a partir del uso de la primera persona, en la historia del personaje-narrador llamado G, el cual es una especie de alter ego del autor.

En la novela La ninfa inconstante, Cabrera Infante detalla el uso de la primera persona en su escritura:

Contar (es decir, contando) implica correr riesgos. Uno de ellos es el riesgo que se corre en la vida, donde uno no cuenta. La vida está siempre en primera persona, aunque uno no sabe cómo va a ser, en un final, el final. La tercera persona, qué duda cabe, es más segura. Pero es también la transmisión a distancia que resulta siempre falsa. La falsa distancia es de la novela, la proximidad de la primera persona viene de la vida. La tercera persona no va a ninguna parte. Todo es ficción, pero la primera persona, tan singular, no lo parece (CABRERA INFANTE, 2008, p. 14).

El autor cubano al decir que la vida se vive en la primera persona parece estar consciente que textos que buscan una aproximación entre la historia de vida del narrador y del autor producen, en las palabras de Diana Klinger (2007, p. 22), una "visibilidade do privado, uma espetacularização da intimidade". En este sentido, la tercera persona, para Cabrera Infante, no provoca duda sobre su veracidad, pues dice respecto a una ficcionalización del otro y por eso no hay duda sobre quién habla. Por lo contrario, un texto ficcional, escrito en primera persona, según el propio Cabrera Infante, es ficción, pero no lo parece. Ahí tenemos el juego entre realidad y ficción. Para Iván Darancou (2014, p. 469):

En este sentido, sin embargo, Cabrera Infante construye una topografía, un mapeo en el discurso, pero también en el mundo físico, conectando los topoi físicos de los 
lugares que reconstruye con los topoi retóricos de sus memorias y sus vivencias. Que el evento haya sucedido en alguna realidad tangible y comprobable resulta, como destaca Cabrera Infante, imposible de comprobar. Pero en su memoria - y eso es lo que importa para efectos de construcción de subjetividades y de realidades borradas por la historia -, sí sucedió.

Autoficciones no son textos documentales que tienen el compromiso de registrar la verdad histórica validada por los historiadores. Eses textos de naturaleza ficcional, al retratar narrativas de vidas individuales o colectivas, se acercan de la realidad empírica y confunden el lector sobre los límites de estas escrituras. No se puede establecer dónde empieza la realidad o dónde termina la ficción, pues "habrá momentos en que el ojo que lee no creerá lo que ve. Eso se llama ficción. Pero es necesario que el lector confunda el presente de la lectura con el pasado de lo narrado" (CABRERA INFANTE, 2008, p. 12). Por eso, Philippe Gasparini (2014, p.187) llama la atención:

\footnotetext{
Não se tratava de uma simples brincadeira com as palavras. O conceito de autoficção teve inicialmente como base uma ontologia e uma estética da escrita do eu. Ele postulava que não é possível se contar sem construir um personagem para si, sem elaborar um roteiro, sem dar "feição" a uma historia. Postulava que não existe narrativa retrospectiva sem seleção, amplificação, reconstrução, invenção.
}

Se aceptamos la idea de que es imposible contar una historia sin crear un personaje o un guión ficticio, estableceremos un pacto de lectura (LEJEUNE, 2008) de La ninfa inconstante como una gran novela autoficcional latinoamericana, pues "como toda ficción es siempre érase una vez, esta narración mía no puede ser menos" (CABRERA INFANTE, 2008, p. 13) que una autoficción. Considerando esta discusión conceptual, pasemos a realizar un análisis de la fábula cubana.

Tras el Prólogo, la novela de Cabrera Infante empieza con una explicación sobre el pasado, como característica de una escritura autoficcional, pues "escribir, lo que hago ahora, no es más que una de las formas que adopta la memoria. Lo que escribo es lo que recuerdo - lo que recuerdo es lo que escribo" (CABRERA INFANTE, 2008, p. 19). Este debate sobre la memoria nos permite decir que La ninfa inconstante significa el retorno a una Habana del pasado, que "era para mí entonces una isla encantada de la que era a la vez explorador y guía" (CABRERA INFANTE, 2008, p. 21). En esta isla, la historia empieza con la muerte de una joven llamada Stella Morris:

Ella murió. ¿Se suicidó? No, murió de la muerte más innatural: muerte natural. La mató en todo caso el tiempo. Pero lo cierto, lo terrible, lo definitivo es que Estelita, Estela, Stella Morris está muerta. Ahora soy yo el que reconstruyo su memoria. Ella 
era una persona pero ha terminado convertida en ese destino terrible, un personaje. Hay que decir que ella era todo un personaje (CABRERA INFANTE, 2008, p. 20).

El narrador desea, en este comienzo del enredo, contar la historia de Stella. Sin embargo, esta mujer que, según las palabras del narrador, al convertirse en personaje, ya que no se puede contar algo sin crear un personaje (GASPARINI, 2014), posibilita que el narrador narre su propia historia, con las siguientes palabras: “digo que no la conocí y debo decir que la encontré; en la calle, una tarde, cuando era una despistada de los suburbios en el centro de La Habana, perdida. Pero para mí fue un encuentro" (CABRERA INFANTE, 2008, p. 20). En este sentido, se podría cuestionar la razón por la cual la historia de Stella es elaborada desde la perspectiva de un hombre y así el narrador esclarece: "No creo que esté mal que la historia de una mujer empiece con un hombre porque ese hombre no fue de ninguna consecuencia para mí, pero la mujer sí. Además la mujer era entonces una muchacha" (CABRERA INFANTE, 2008, p. 20).

En este momento de la historia, ya queda claro que no se trata de una novela que va a contar exclusivamente la historia particular de la vida de Stella Moris. Por lo contrario, La ninfa inconstante también nos presenta a la vida del narrador G. Estos eventos reelaborados, aunque hagan referencia a Stella son, en realidad, momentos vividos por este narrador-protagonista. En este sentido, la trama pasa en la ciudad de La Habana y la novela nos regala con imágenes de la isla, en su cotidiano:

El mar allá abajo era del color del cielo sin nubes, solo que era denso, intenso. Estaba además mechado de otros azules que eran estrías esmeralda, azul cobalto, azul, azul y, al fin, marino. Al fondo, el Malecón era un telón pintado de recortado que se veía el paisaje marino. El Malecón y el muro eran de color arena que parecía una playa de cartón piedra aunque era de doble cemento armado. Ahí en el Malecón terminaba La Habana. El resto es el mar (CABRERA INFANTE, 2008, p. 28)

El color azul del mar caribeño forma una imagen tropical de esta pequeña isla, cuyo Malecón divide a la ciudad del mar. En esta parte de La Habana, conocida por el turismo, por los bares y por la presencia de muchos visitantes extranjeros, G. encuentra a Stella Moris por primera vez: "Era rubia. No: rubita. Ella estaba allí a la sombra, pero el pelo, el cutis y sus ojos brillaban como si le cayera un rayo de sol para ella sola" (CABRERA INFANTE, 2008, p. 28). En esta descripción de Stella, el uso del diminutivo en la palabra "rubita" muestra que se trata de un joven personaje y que el protagonista está consciente que no es una mujer adulta, pero una chica y, así mismo: "La miré. De cerca ella bizqueaba un poco y se veía muy joven, casi una muchachita” (CABRERA INFANTE, 2008, p. 41). En el Malecón, los dos se conocen, y la charla es interrumpida por un beso: 
Dame un beso - pidió ella.

La besé. Nos besamos, con los labios apretados, cerrados, sellados. Si le hubiera abierto los labios con mi lengua obscena tal vez no le gustaría. Besarse es más complicado de lo que parece. Besos que educan, besos que caducan (CABRERA INFANTE, 2008, p.43).

Es interesante verificar una imagen producida a partir de este beso. A G. le gustaría besarla con su "lengua obscena", lo que significa que él era un hombre más vivido, mientras que Stella era todavía una muchacha que empezaba a descubrir la potencia de su cuerpo. A partir de entonces, el protagonista se enamora de Stella Moris e intenta conquistarla con palabras, versos y referencias literarias, como podemos ver en la cita siguiente:

\footnotetext{
Dices las cosas más raras.

Es el amor.

¿Cómo puedes hablar de amor si apenas me conoces? Van Gogh.

Así es el amor. Ciego como Bach, sordo como Beethoven, muengo como

Uy. Tanta gente.

Voy a explicarte. Bach era marido de Anna Magdalena, Beethoven se volvía loco con su sobrino, Van Gogh se hizo el loco por Gauguin.

¡Dios mío! Me matas con tu agrupación (CABRERA INFANTE, 2008, p. 47).
}

Como dicho, G. era un crítico de cine, un verdadero intelectual latinoamericano que intentaba seducir a Stella con su vocabulario y sus referencias culturales. Sin embargo, Stella era una sencilla muchacha cubana que andaba por el Malecón en los días del verano caribeño divirtiéndose. Se molestaba con el modo por el cual G. se comunicaba con ella y reclamaba: “yo no sé una sola palabra de inglés" (CABRERA INFANTE, 2008, p. 45), mientras que G. le hablaba sobre Romeo y Julieta, de Shakespeare, por ejemplo. Enamorado, el protagonista llega a crear algunas definiciones para lo que sentía por la muchacha:

\begin{abstract}
Amar quiere decir, según el bolero, encontrar su diosa. Amar es algo sin nombre que encadena a un hombre con una mujer. Es decir, elevar lo divino a través de ella. Amar es el plan de la vida, amor esa cosa divina. Ardor aumentado: pubertad nueva, adoración de nuevo. Sentí un pánico nuevo, una angustia. En lugar del estómago tenía un vacío, un obstinado abismo. No hay duda, me había enamorado, estaba enamorado y el amor era como una luna invisible allí donde la luna es más visible. Dios mío, ¿era esto después de todo el amor? (CABRERA INFANTE, 2008, p. 66).
\end{abstract}

En esta citación, percibimos un sentimiento de soledad del protagonista de la novela que, al mencionar que amar es encontrar su diosa, está señalando la importancia de tener una persona que pueda rellenar el espacio de la soledad en su rutina. A este respecto, Milan (1999, p. 23) dice que: “o amor não vive sem a falta, sem o mal infligido pela ausência. O que seria 
dele sem a solidão?”. Es importante recordar que G. no vive solo y, aunque casado, encontró en Stella una mujer que puede acabar con su soledad. Pero, es fundamental mencionar que ella no era una mujer adulta y a lo largo de una charla entre los dos, su edad es descubierta:

\footnotetext{
Ella me miró de abajo arriba como si me mirara de arriba abajo.

$\mathrm{O}$ tú eres un tonto. O te haces el tonto, que es peor. ¿No te das cuenta que no tengo dieciséis?

Dios mío. Dieciséis es el límite del consentimiento de las mujeres. Ella era una menor y nunca me lo había dicho hasta ahora. ¡Ella no tenía dieciséis años! Estupor, estupro. Eso quiere decir un año, ocho meses y veintiún días en la cárcel más cercana. (CABRERA INFANTE, 2008, p. 68).
}

Podemos notar dos visiones para el mismo diálogo. Inicialmente, Stella pregunta si G. es tonto por, presuntamente, no haberse dado cuenta de que ella no tenía ni dieciséis años de edad. Por otro lado, tenemos la segunda perspectiva para el diálogo cuando el personaje percibe que podrá irse a la cárcel por haber cometido un delito - o sea, que él sabía que Stella era una muchacha.

El protagonista de la novela de Cabrera Infante, además de enamorarse de la ninfa, demuestra una obsesión por ella: "Mujer, si tú puedes con Dios hablar, pregúntale si yo alguna vez, te he dejado de adorar" y, por eso, Barthes $(2007$, p. 23) afirma que "o discurso amoroso, ordinariamente, é um manto liso que adere à imagem, uma luva macia que envolve o ser amado". G intenta ilusionar a Stella Moris acerca de su sentimiento por ella y eso no significa que él no estuviese de hecho enamorado, pero que su dulce discurso podría provocar en Stella una gran pasión. Sin embargo, otras definiciones para el amor aparecen en la narrativa: "Entonces supe que el amor no es más que una coincidencia fatal: estar en un lugar adecuado en un tiempo torpe, inadecuado y totalmente inhóspito. El amor es un efecto sin causa" (CABRERA INFANTE, 2008, p. 81).

El día que Stella cumplió dieciséis años de edad, los dos fueron hacer amor en una posada y con eso G. se tranquilizaba: "No me preocupa ya la ley contra el estupro" (CABRERA INFANTE, 2008, p. 109). Otra cosa le preocupaba, su mujer. Así, G. decide llamarla por teléfono:

\footnotetext{
¿Cuándo vuelves?

Para eso te llamo. No voy a volver. Me he furtivado.

Ese término escolar para fugarse no le hizo gracia.

Por favor, ¿qué quieres decir?

Quiero decir que no vuelvo, que me rajo, que me he fugado con otra mujer. Oí, como un eco a mi frase, sus sollozos.

Solo te lo digo para que no te preocupes. No me pasa nada. Estoy bien pero no vuelvo. ¿Oíste?
} 
Sí, oí - dijo ella entre sollozos. (CABRERA INFANTE, 2008, p. 110).

Después de haber dejado su mujer entre sollozos, G. y Stella Moris viven una noche de sexo en la posada. En primera persona, notamos que el crítico de cine se vuelve seducido por la ninfa y por su joven cuerpo: "sus tetas, sus teticas, eran minúsculas como su cuerpo" (CABRERA INFANTE, 2008, p. 115). G. estaba ilusionado por el cuerpo de una muchacha virgen. En la posada, Stella se muestra incomodada con la relación sexual, a la vez que ella era una ninfa virgen que nunca hubiera estado con un hombre, hasta que el narrador conmemora:

Tengo que hacerles una confesión que Chéjov objetaría o Dostoyevski aprobaría: Estelita era virgen cuando entró en la posada y había dejado de serla cuando salió: entrar, salir y perder lo que jamás volvería a recuperar (CABRERA INFANTE, 2008, p. 128).

Stella pierde la virginidad tras haberse encontrado con G. en esta posada. El protagonista afirma que "una cosa era notable en Estelita: llevaba el sexo literalmente a flor de piel. La piel dulce. Con labia en su cuerpo" (CABRERA INFANTE, 2008, p. 146). Aquí percibimos un cambio discursivo en G. En un primer momento el protagonista menciona que el amor era lo más importante en el contacto con Stella. Ahora vemos que el sexo se transforma en el tema fundamental de la narrativa, mayoritariamente a partir la opinión del protagonista y hasta aquí poco se habla de la visión de la muchacha. Tras el desarrollo de la historia, tenemos una confesión de G:

\footnotetext{
Por raro que parezca (y aun hoy me parece extraño), esa noche en la posada fue la última vez que hicimos el amor. (De hecho nunca singamos. Singar esa perfecta palabra habanera: la carne hecha verbo). Toda nuestra relación fue un largo coitus interruptus que nunca completamos. Hacer el amor, esa otra clase de amor, fue un intenso abortado varias veces. Siempre intenté la felicidad con ella, pero ella a veces se interpuso [...] Ella, por su parte, repudió mi sentimiento: nunca conocí a nadie que se tuviera menos lástima. Para ella su vida no era mala ni buena, solamente era la vida (CABRERA INFANTE, 2008, p. 212).
}

Stella y G. tuvieron una noche de sexo en la posada. Según el propio narrador, esta no fue una noche de amor, pues no ha pasado de un "coitus interruptus". Stella no quiso seguir la relación amorosa con G. y así nos parece que ella solo estuvo curiosa acerca de cómo sería pasar una noche con el hombre en la posada. Para Stella, nada más que eso, para G. una decepción porque "Stella era entonces (la aliteración no es una alteración) un personaje de la novela de ella misma" (CABRERA INFANTE, 2008, p. 230). En un primer momento, La ninfa inconstante se limita a contar la vida de G., pero en los episodios finales de la novela, la experiencia sexual de Stella se convierte en el eje central de la trama: 
Tu antigua virgen y amante es ahora lesbiana. Ve que te imito y evito decir que soy tortillera. Pero no es lo que lo sea ahora. Siempre, querido, lo fui. Solo que no lo sabía. Tú me descubriste, me ayudaste a descubrirme a mí misma. ¿Cómo es que me decías y repetías, que eras mi Cristóbal? No me importa - me dijo ella con su voz finita que venía del infinito - si te gusta o no te gusta lo que hago. Tu opinión es indiferente. Es más, tú me eres indiferente (CABRERA INFANTE, 2008, p. 268).

Después de haber hecho sexo con G., Stella se descubre lesbiana. La narrativa que ponía a G. como un gran seductor, capaz de conquistar a una muchacha con palabras y versos de boleros, cambia de perspectiva. Ahora vemos la experiencia de Stella con su cuerpo, con su deseo y con sus subjetividades. Además de eso, si antes veíamos una muchacha despistada que no hablaba una sola palabra de inglés y que tampoco conocía referencias culturales y literarias, Stella ahora es una mujer decidida a vivir su vida lejana de G. Por eso, la novela se acaba con esa imagen: "Muy pocas cosas se pierden en el tiempo, pero muchas pueden perderse en el espacio. La Habana es una gran ciudad, pero no es una ciudad grande. Sin embargo, a pesar de no salir de ella y salir mucho, no volví a ver a Estela" (CABRERA INFANTE, 2008, p. 282).

\section{Palabras finales}

En este artículo realizamos un análisis de la novela póstuma La ninfa inconstante (2008), escrita por el escritor cubano Cabrera Infante, desde la perspectiva de los estudios autoficcionales, cuya trama narra el encuentro entre el personaje protagonista G. y una muchacha llamada Stella Moris, en el Malecón, en La Habana.

Esta es una narrativa que recupera parte del pasado de Cabrera Infante a partir de la escritura en primera persona, de naturaleza autoficcional. De este modo, estamos de acuerdo con Iván Darancou (2014, p. 475), cuando afirma que "Cabrera Infante recurre a la memoria, con el conocimiento de que su recorrido será solo un viaje hacia el interior de sí mismo". Por eso, toda la historia narrada, aunque ponga en evidencia la vida privada de Stella Moris, se propone a reelaborar la memoria del personaje-protagonista de Cabrera Infante sobre sus amores en Cuba.

Así, también concordamos que La ninfa inconstante es un texto de catarsis (DARANCOU, 2014), a la vez que la narrativa, al movilizar la memoria del narrador, posibilita captar imágenes de Cuba y, particularmente, de La Habana. Para concluir, merece la pena traer una citación más de la novela: 
Estela y yo estamos unidos en este libro, en esta página, en estas palabras que se suceden. Un abismo nos une: ella murió y yo vivo para escribir este libro. Nos salvará este paraíso, nos condenará este infierno: un libro, la vida. De verdad, verdugo nunca fue mi tarea más temida, y encontré entre las cenizas de mi amor su corazón intacto" (CABRERA INFANTE, 2008, p. 270).

Por un momento, nos parece que contar la vida de G. implica también narrar la historia de Stella Moris. Lo único que pasa es que, para G., la joven muchacha que caminaba por el Malecón, en La Habana, murió, mientras que él se ocupa de reelaborar este momento de su vida en un libro. Al fin, su corazón siguió intacto y la vida siguió su rumbo, así como Stella Moris.

\section{Referéncias}

ALBERCA. M. ¿Existe la autoficción hispanoamericana? Cuadernos del CILHA, n. 07, 2006.

BARTHES, R. Fragmentos de um discurso amoroso. Rio de Janeiro: Francisco Alves, 2007.

CABRERA INFANTE, G. La ninfa inconstante. Barcelona: Galaxia Gutenberg, 2008.

CABRERA INFANTE, G. Así en la paz como en la guerra. Madrid: Espasa Calpe, 1960.

CABRERA INFANTE, G. Tres tigres tristes. Colección Biblioteca Hispanoamericana del Siglo XX. Madrid: Espasa Calpe, 1965.

CABRERA INFANTE, G. Vista del amanecer en el trópico. Barcelona: Galaxia Gutenberg, 1974.

CABRERA INFANTE, G. Todo está hecho con espejos. Barcelona: Galaxia Gutenberg, 1999.

CABRERA INFANTE, G. Mea Cuba. Barcelona: Plaza \& Janés/Cambio 16, 1992.

CABRERA INFANTE, G. Holy Smoke. Barcelona: Galaxia Gutenberg, 1985.

CABRERA INFANTE, G. Un oficio del siglo XX. Barcelona: Galaxia Gutenberg, 1963.

CABRERA INFANTE, G. Arcadia todas las noches. Barcelona: Galaxia Gutenberg, 1978.

CABRERA INFANTE, G. Cine o sardina. Barcelona: Galaxia Gutenberg, 1997.

DARANCOU, I. Memoria e identidad (auto)biográfica en La ninfa inconstante de Guillermo Cabrera Infante. Hispanic Review, v. 82, n. 4, 2014.

GASPARINI, P. Autoficção é o nome de quê? In: NORONHA, J. M. G. Ensaios sobre a autoficção. Belo Horizonte: Editora UFMG, 2014.

KLINGER, D. Escritas de si, escritas do outro: o retorno do autor e a virada autobiográfica. Rio de Janeiro: 7Letras, 2007. 
LEJEUNE, P. O pacto autobiográfico: de Rousseau à Internet. Belo Horizonte: UFMG, 2008. MÁRQUEZ, G. G. Memoria de mis putas tristes. Cali: Grupo Editorial Norma, 2004. MILAN, B. O que é o amor. Rio de Janeiro: Record, 1999.

MOLLOY, S. Vale o escrito: a escrita autobiográfica na América Hispânica. Chapecó: Argos, 2003.

NORONHA, J. M. G. Ensaios sobre a autoficção. Belo Horizonte: Editora UFMG, 2014.

Recebido em: 14/05/2020 Aceito para publicação em: 02/09/2020 